\title{
PD-L1 and IAPs co-operate to protect tumors from cytotoxic lymphocyte-derived TNF
}

\author{
Conor J Kearney ${ }^{\star, 1,2,5}$, Najoua Lalaoui ${ }^{3,4}$, Andrew J Freeman ${ }^{1}$, Kelly M Ramsbottom ${ }^{1}$, John Silke ${ }^{3,4}$ and Jane Oliaro ${ }^{*, 1,2,5}$
}

Smac-mimetics are emerging as promising anti-cancer agents and are being evaluated in clinical trials for a variety of malignancies. Smac-mimetics can induce TNF production from a subset of tumor cells and simultaneously sensitize them to TNF-induced apoptosis. However, TNF derived from other cellular sources, such as cytotoxic lymphocytes (CLs) within the tumor, may also contribute to the anti-tumor activity of SMs. Here, we show that CD8 ${ }^{+} \mathrm{T}$ cells and NK cells potently kill tumor cells in the presence of the SM, birinapant. Enhanced CL killing occurred through TNF secretion upon tumor antigen recognition or NK-activating receptor ligation. Importantly, the perforin/granzyme route to CL-mediated tumor cell killing was dispensable for the efficacy of birinapant, emphasizing the importance of the TNF-mediated apoptosis pathway. Time-lapse microscopy revealed that birinapant sensitized tumor cells to apoptosis as bystanders and to membrane-bound TNF delivered to tumor cells within the immunological synapse. Furthermore, PD-L1 expression on tumor cells suppressed antigen-driven TNF production by CD8 ${ }^{+}$ T cells, which could be antagonized through PD-1 blockade. Importantly, the elevated levels of TNF produced upon PD-1 blockade further enhanced tumor cell killing when combined with birinapant. The combined anti-tumor activity of IAP antagonism and PD-1 blockade occurred independently of perforin-mediated tumor cell death. Taken together, we identify CL-derived TNF as a potent effector of birinapant mediated anti-tumor immunity and opportunity for combination therapy through co-inhibition of immune checkpoints.

Cell Death and Differentiation (2017) 24, 1705-1716; doi:10.1038/cdd.2017.94; published online 30 June 2017

Inhibitor of apoptosis (IAP) proteins regulate diverse cellular functions including mitosis, migration, apoptosis, and signal transduction events that promote inflammation., ${ }^{1,2}$ IAPs are defined by the presence of Baculoviral IAP Repeat (BIR) domains that facilitate their interaction with caspases to suppress apoptosis. Endogenous and synthetic IAP antagonists, such as Smac/Diablo and Smac-mimetics (SMs), respectively, can promote apoptosis upon interaction with IAP BIR domains. ${ }^{2,3}$ Several IAP family members, such as the cellular IAPs (CIAP1/2) and XIAP, also possess a RING domain with E3 ubiquitin ligase activity, facilitating their involvement in signal transduction pathways. ${ }^{1,2}$ Although XIAP can directly inhibit effector caspase protease activity, ClAP1/2 do not. ${ }^{4}$ Instead, clAP1/2 restrain apoptosis induced by members of the TNF superfamily, including TNF itself, by initiating pro-survival canonical nuclear factor $\kappa B$ (NF- $k B$ ) activation and inhibiting the formation of death signaling complexes such as the Ripoptosome. As a result, several groups have shown that SM can sensitize tumor cells toward TNF-dependent apoptosis..$^{5-8}$ Indeed, several pharmaceutical companies have developed SMs and their clinical potential as cancer therapies, either as single agents, or in combination with other cytotoxic agents is being evaluated.

SMs display single agent efficacy against some tumors and leukemias. ${ }^{9,10}$ This occurs via SM-induced TNF secretion, which acts in an autocrine fashion to kill the tumor cells in the absence of the clAP1/2-mediated survival pathway., ${ }^{6,711}$ However, TNF or other cytokines, supplied by immune cells are likely to contribute to SM efficacy, especially in tumors that fail to produce TNF upon IAP loss. ${ }^{12-17}$ In support of this concept, SMs are more efficient in vivo when combined with inflammatory adjuvants, which promote immune cell-derived TNF secretion. ${ }^{15,18}$ Similarly, IAP antagonism promotes antitumor immunity in myeloma, independently from cell death induction. ${ }^{14}$ Therefore, although the mechanism by which SMs function in vivo is more complex than initially appreciated, combination therapies that boost immunity, particularly in the context of elevated TNF secretion, are likely to synergize with SMs.

Cytotoxic lymphocytes (CLs), including $\mathrm{CD}^{+} \mathrm{T}$ cells and natural killer (NK) cells are required for anti-tumor immunity and contribute to the efficacy of many cancer therapeutics. ${ }^{19,20}$ $\mathrm{CD}^{+} \mathrm{T}$-cell infiltration into diverse tumor types directly predicts patient prognosis. ${ }^{21-23}$ Similarly, proper NK cell function is required for tumor immune-surveillance, ${ }^{24}$ and is usually impaired in late-stage hematopoietic malignancy. ${ }^{25,26} \mathrm{CLs}$ clear tumors through a combination of direct perforin/granzymemediated cytotoxicity, amplifying anti-tumor immune responses via secretion of inflammatory cytokines such as TNF and through IFN $\gamma$-mediated tumor cytostasis. ${ }^{27-29}$ However, CLs often adopt an 'exhausted' phenotype within the tumor micro-environment, characterized by decreased effector

\footnotetext{
${ }^{1}$ Immune Defence Laboratory, Cancer Immunology Division, The Peter MacCallum Cancer Centre, Melbourne, VIC 3000, Australia; ${ }^{2}$ Sir Peter MacCallum Department of Oncology, The University of Melbourne, Parkville, VIC 3052, Australia; ${ }^{3}$ Cell Signalling and Cell Death Division, The Walter and Eliza Hall Institute for Medical Research, $1 \mathrm{G}$ Royal Parade, Parkville, Melbourne, VIC 3050, Australia and ${ }^{4}$ Department of Medical Biology, University of Melbourne, Parkville, VIC 3050, Australia

*Corresponding author: CJ Kearney or J Oliaro, Immune Defence Laboratory, Cancer Immunology Division, The Peter MacCallum Cancer Centre, Melbourne, VIC 3000 , Australia. Tel: +61 3855 97094; E-mail: conor.kearney@petermac.org or jane.oliaro@petermac.org

${ }^{5} \mathrm{Co}$-senior authors.

Received 24.2.17; revised 18.4.17; accepted 08.5.17; Edited by T Mak; published online 30.6.17
} 
function (cytotoxicity and cytokine production) and elevated expression of the inhibitory receptor PD-1. ${ }^{30-32}$ T-cell-driven immune responses are finely tuned by immune checkpoint receptors, including the PD-1/PD-L1 axis that serves to downregulate effector function and prevent excessive inflammation during infection. ${ }^{33-35}$ It is now clear however, that many a

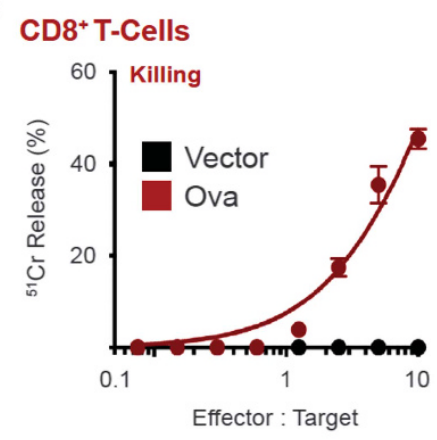

c CD8 $^{+}$T-Cells

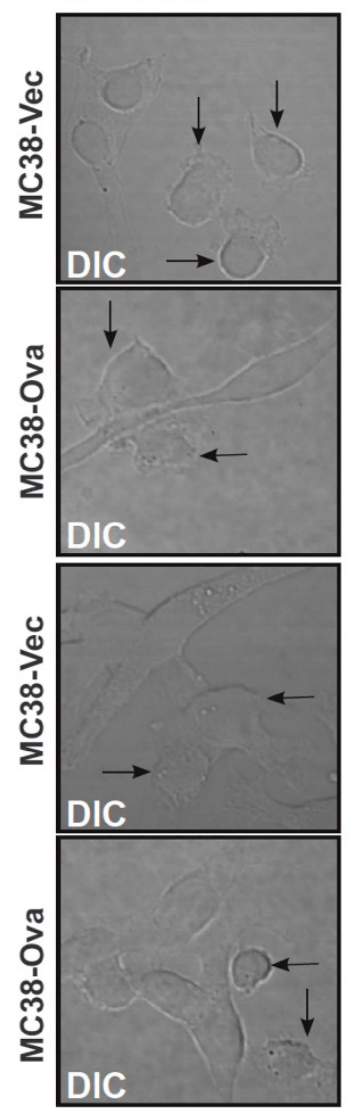

f Human KHYG1 NK

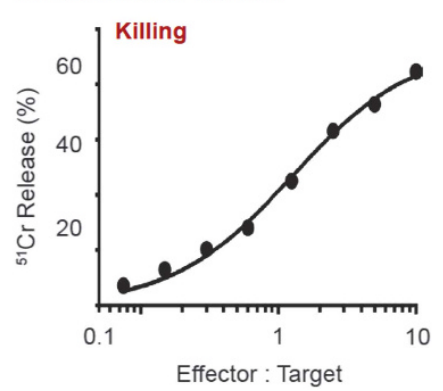

b
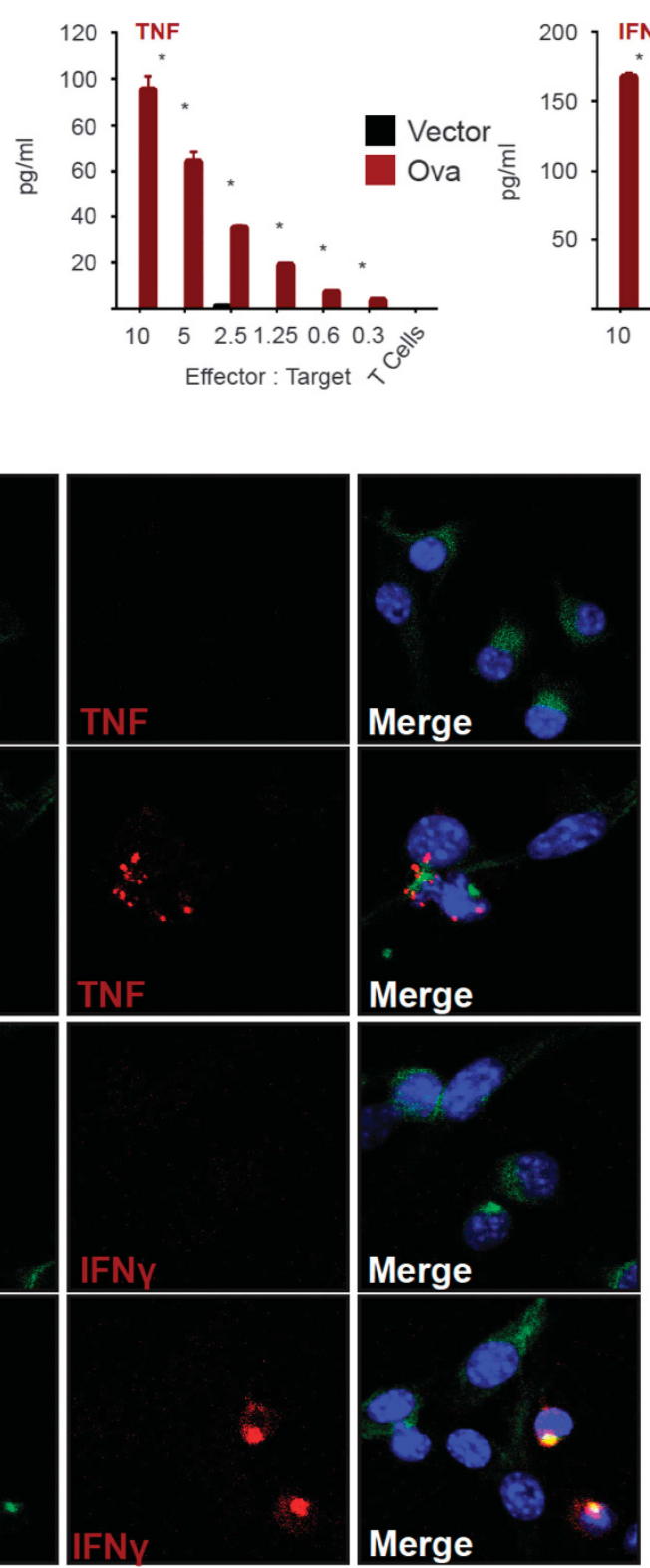

d
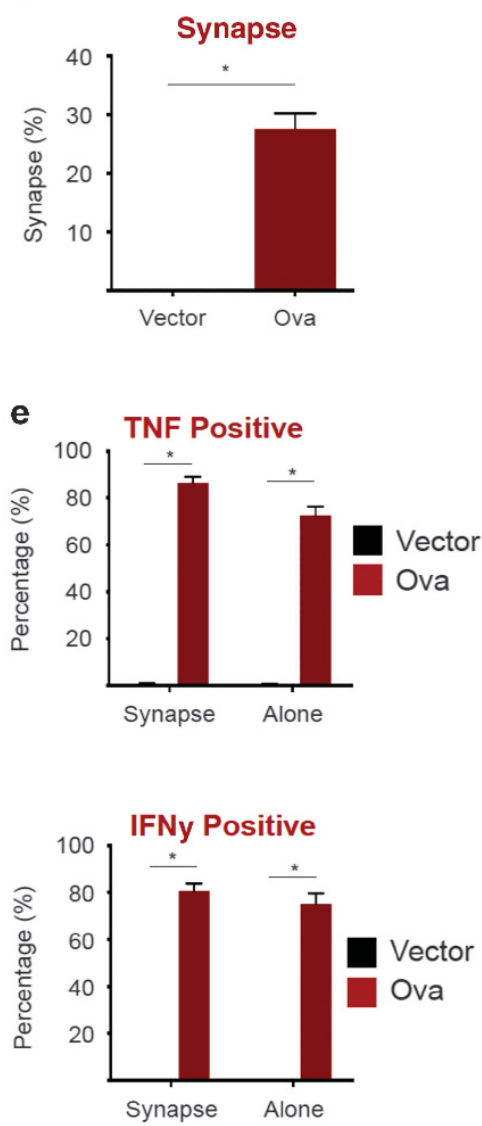

g

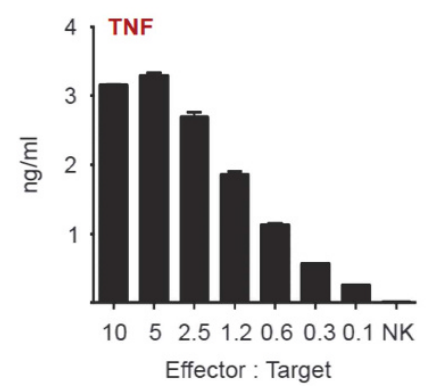

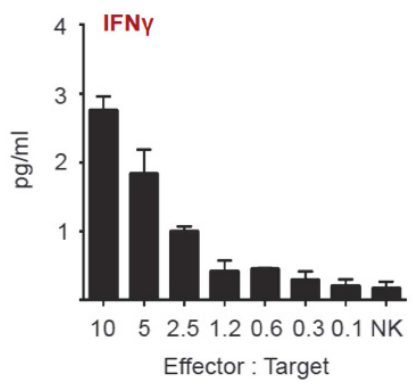


tumors upregulate PD-L1 expression as a mechanism to antagonize CL-mediated anti-tumor immunity. ${ }^{32}$ Indeed, immune checkpoint blockade therapies have been successfully used in the clinic through reversing $\mathrm{CD}^{+}$T-cell exhaustion and re-instating effector function. ${ }^{30,32,36}$ However, whereas many studies have focused on the ability of checkpoint blockade therapies to enhance the activation state of $\mathrm{CD}^{+} \mathrm{T}$ cells, few studies have considered the anti-tumor effects of elevated TNF secretion upon immune checkpoint blockade.

A number of SMs, including birinapant, are currently in phase I/II clinical trials for a variety of cancer types (https:// clinicaltrials.gov). Because SMs function in a TNF-dependent manner, and PD-1/PDL-1 blockade can enhance TNF secretion by $\mathrm{CD}^{+} \mathrm{T}$ cells, ${ }^{36}$ we examined if birinapant could enhance the anti-tumor activity of CLs.

\section{Results}

CLs produce inflammatory cytokines upon tumor cell recognition. Effector $\mathrm{CD}^{+} \mathrm{T}$ cells recognize tumor cells through the specific interaction between the T-cell receptor (TCR) and tumor antigens presented on MHC-I molecules. TCR engagement by its cognate antigen within the immunological synapse triggers signaling cascades that promote polarization of the microtubule organizing centre (MTOC) and lytic granules to the synaptic cleft to drive cell death via the perforin/granzyme pathway ${ }^{37,38}$ and NF- $\kappa$ B-dependent production of inflammatory cytokines. ${ }^{37,38}$ OT-I TCR transgenic $\mathrm{CD}^{+} \mathrm{T}$ cells efficiently lyse MC38 tumor cells stably expressing the OT-I antigen, ovalbumin (Ova, Figure 1a) and secrete abundant amounts of the inflammatory cytokines, TNF and IFN $\gamma$, (Figure $1 \mathrm{~b}$ ). $\mathrm{CD}^{+} \mathrm{T}$ cells formed an efficient immunological synapse with tumor cells in the presence (MC38-Ova), but not absence, of Ova (MC38Vec), as evident from translocation of the MTOC toward the CL-tumor contact site (Figure 1c, quantitated in 1d). Localization of TNF and IFN $\gamma$ at the synapse was observed in T-cell-tumor cell conjugates, and in bystander $\mathrm{T}$ cells (Figure 1e). These data demonstrate that effector CD8+ T cells continue to express abundant levels of TNF and IFN $\gamma$, even after completion of tumor cell lysis.

NK cells recognize tumor targets via a complex network of activating and inhibitory receptors. If activation signals dominate inhibitory signals within the immunological synapse, NK effector function is triggered. ${ }^{37,38}$ Human KHYG1 NK cells efficiently lysed HeLa cell targets (Figure 1f), and similar to $\mathrm{CD}^{+} \mathrm{T}$ cells, also released TNF and IFN $\gamma$ under these conditions (Figure 1g). Taken together, these data demonstrate that CLs concurrently lyse target cells and release inflammatory cytokines.
CL killing is potentiated by IAP antagonism. Recent evidence suggests that SMs function, at least in part, by enhancing anti-tumor immunity. ${ }^{14,15,18}$ To investigate whether SMs modulate CL killing, we performed a CD8 ${ }^{+}$T-cell killing assay in the presence or absence of birinapant. We initially used a $4 \mathrm{~h}$ chromium release assay, in which tumor cell killing kinetics are entirely perforin dependent. Under these conditions, we observed no modulation of killing kinetics (Figure 2a, quantitated on right). Thus, birinapant does not directly modulate perforin-dependent killing. However, CLs can kill tumors through perforin-independent mechanisms, which invoke apoptosis at a slower rate in comparison with perforin/granzyme delivery. Interestingly, over $18 \mathrm{~h}, \mathrm{CD}^{+}$ T-cell killing of MC38-Ova tumors was enhanced almost fivefold in the presence of birinapant compared with the control (Figure $2 b$, quantitated on right). Similarly, birinapant did not modulate mouse NK cell perforin-dependent killing of MC38 target cells (Figure 2c, quantitated on right). However, over $18 \mathrm{~h}$, NK cell killing function was enhanced about 2.5-fold in the presence of birinapant (Figure 2d, quantitated on right). Indeed, we observed a dose-dependent increase in MC38-Ova killing in the presence of a fixed number of CD8 ${ }^{+}$ T-cell or exogenously added TNF (Supplementary Figure S1a \& S1b). We also observed similar results using an alternative smac mimetic BV6 (Supplementary Figure S1c \& S1d). These observations also translated to a human system, where birinapant enhanced human NK cell lytic function almost sixfold (Figure 2e, quantitated on right).

To determine whether birinapant enhanced CL killing in a TCR-MHC-I dependent manner, we compared killing kinetics of MC38-Ova or vector-expressing cells, in the presence or absence of birinapant. In this instance, birinapant failed to enhance $\mathrm{CD}^{+}$T-cell killing in the absence of antigen recognition, indicating that it only promotes perforinindependent $\mathrm{CD}^{+}$T-cell killing upon TCR engagement by cognate antigen (Figure $2 \mathrm{f}$, quantitated on right).

Perforin-independent CL killing can occur through receptor ligation on tumor cells by ligands of the TNF superfamily (TNF, TRAIL and FasL), which are expressed by CLs. ${ }^{39}$ As birinapant sensitizes to TNF-induced killing, we asked if CL-derived TNF was killing tumor cells in the presence of birinapant. To this end, we performed a killing assay in the presence or absence of a TNF-neutralizing antibody. TNF neutralization reduced $\mathrm{CD}^{+}$T-cell killing to $\sim 50 \%$ of controls (Figure 2g, quantitated on right, Supplementary Figure S3), and the birinapant enhancement of killing was completely abolished under these conditions. We observed similar results with NK cells (Figure $2 \mathrm{~h}$, quantitated on right, Supplementary Figure S3). Inhibiting caspase activity in target cells with emricasan ${ }^{9}$ entirely abolished $\mathrm{CD}^{+}$T-cell killing in either the

Figure 1 Cytotoxic lymphocytes produce inflammatory cytokines upon tumor cell recognition. (a) Chromium release assay (4 h) using MC38-Ova cells as targets and OT-I T cells as effectors. (b) MC38-Ova cells were exposed to OT-I T cells at the indicated effector to target (E:T) ratio. After $5 \mathrm{~h}$, cytokines in supernatants were measured by CBA. (c) MC38-Ova or vector cells were seeded in chamber slides then overlaid with OT-I T cells. After $2 \mathrm{~h}$, cells were fixed, stained as indicated, then visualized by confocal microscopy. (d) The percentage of T cells that were in a synapse with a target cell was quantitated by confocal microscopy. (e) The percentage of $\mathrm{T}$ cells that were positive for the indicated cytokines was quantitated by confocal microscopy. A minimum of 100 cells was counted in each condition. (f) Chromium release assay (4 h) using HeLa cells as targets and KHYG1 NK cells as effectors. (g) HeLa cells were exposed to KHYG1 NK cells at the indicated effector to target (E:T) ratio. After $5 \mathrm{~h}$, cytokines in supernatants were measured by CBA. Error bars represent the mean \pm S.E.M. of triplicate determinations from a representative experiment, ${ }^{*} P<0.05$ by unpaired Student's $t$-test 
presence or absence of birinapant (Figure 2i, quantitated on right). Furthermore, we confirmed that birinapant enhanced TNF-induced apoptosis by western blot, which shows accelerated cleavage of caspase 3 and PARP (Figure 2j). Surprisingly, given the literature on Smac-mimetics, birinapant did not increase cytokine secretion from CTL upon target engagement (Supplementary Figure S2). Taken together, these data demonstrate that birinapant does not improve tumor cell killing by increasing CL TNF production but rather harnesses CL-derived TNF to drive tumor cell apoptosis, which markedly improves CL tumor killing potency. a CD8 ${ }^{+}$T-Cells

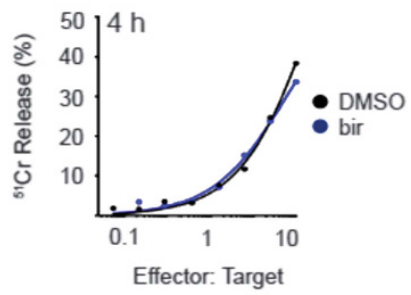

C NK Cells

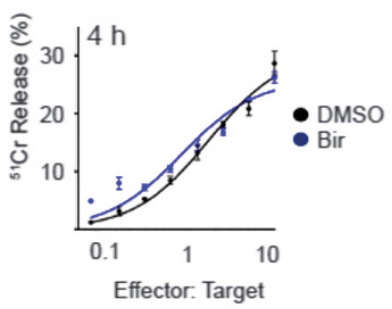

e

Human KHYG1 NK

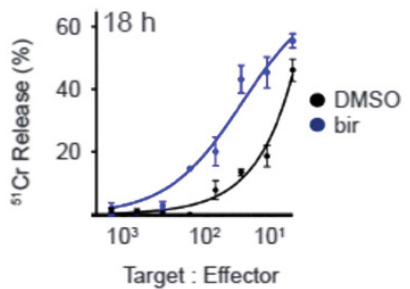

g

CD8 ${ }^{+} \mathrm{T}-$ Cells

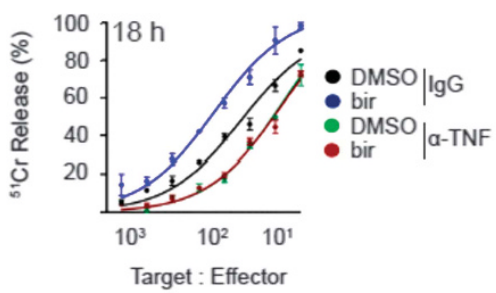

i

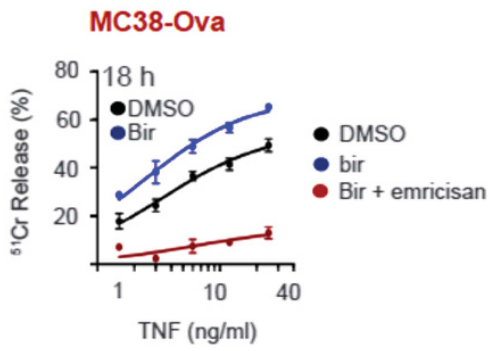

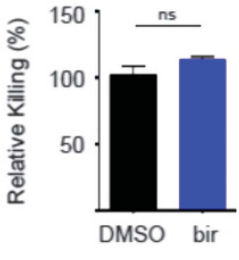
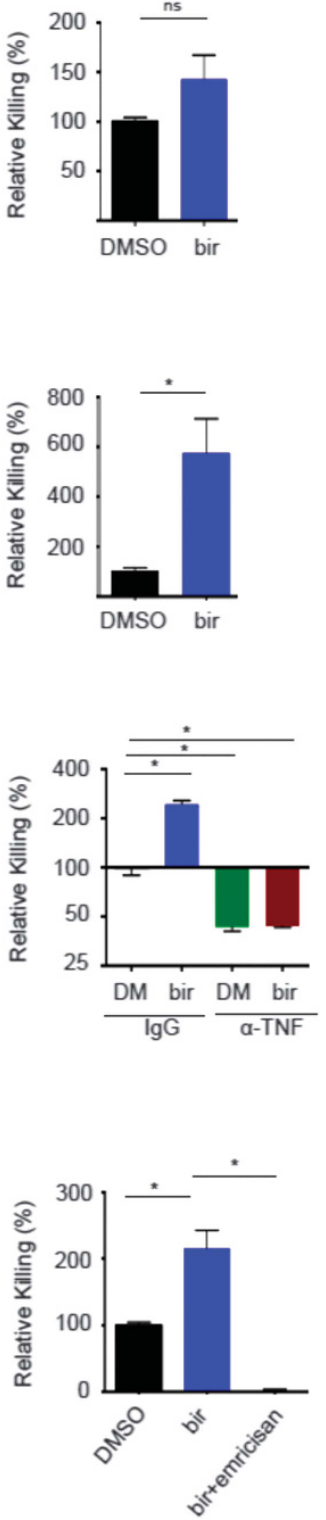

b
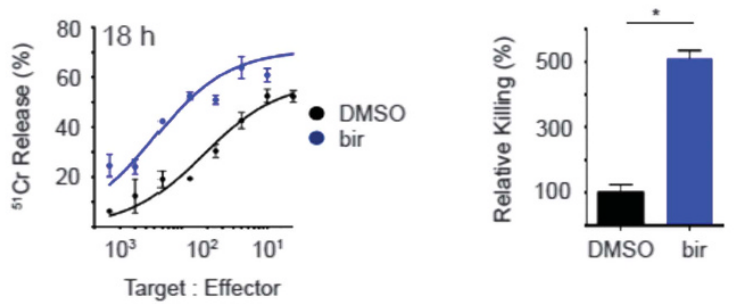

d
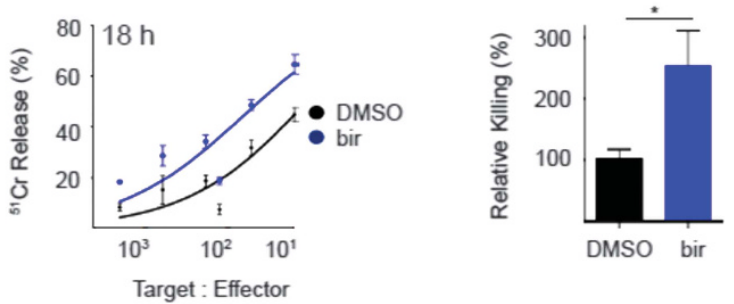

$\mathbf{f}$
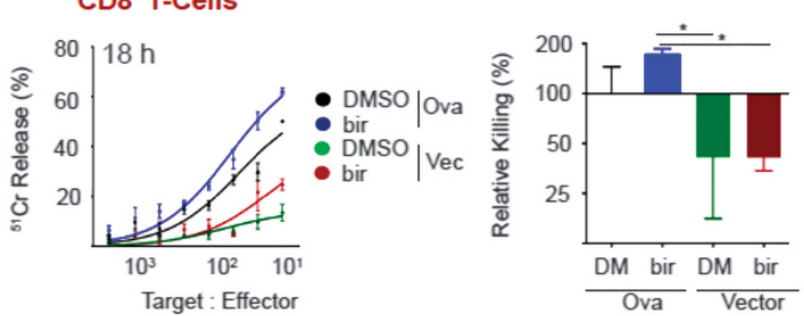

h
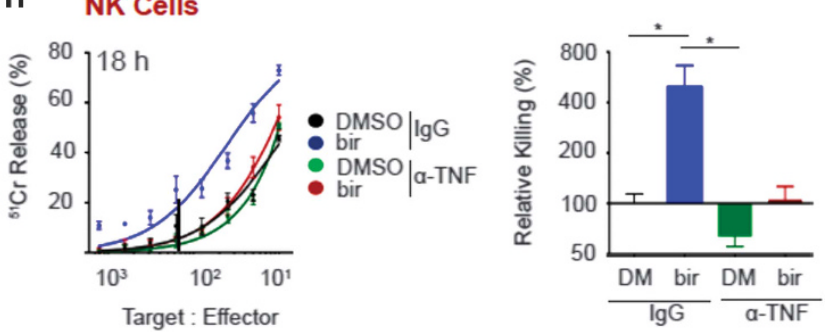

j

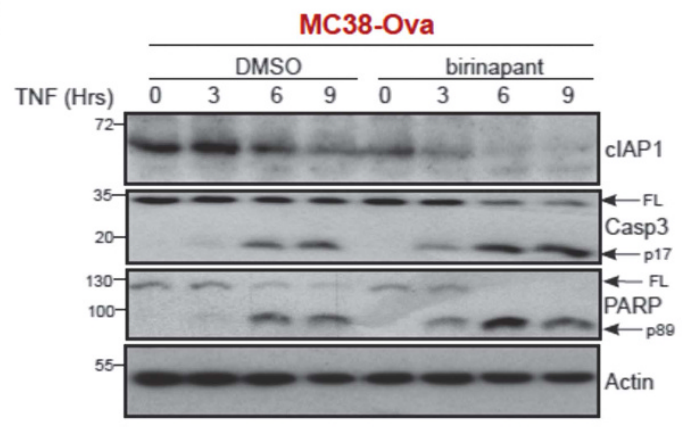


IAP antagonism overcomes failed perforin-dependent killing. Successful perforin/granzyme-dependent tumor cell killing results in detachment of the $C L$ via an unidentified signal generated by caspase activity in the apoptotic target cell. ${ }^{40}$ However, if a CL fails to kill a target due to perforin/ granzyme deficiency, or high levels of apoptosis inhibitory proteins such as XIAP and Bcl2 family members, the absence of a detachment signal drives a prolonged synapse, resulting in inflammatory cytokine hyper-secretion. ${ }^{40}$ Thus, we asked whether antagonizing IAPs could re-route the failed perforindependent pathway to apoptosis to the TNF-induced apoptotic pathway. As previously described, we also observed that $\mathrm{Pfn}^{-1-} \mathrm{CD}^{+} \mathrm{T}$ cells produced significantly more TNF and IFN $\gamma$ than $\mathrm{Pfn}^{+/+} \mathrm{CD}^{+} \mathrm{T}$ cells in the presence of target cells ${ }^{40}$ (Figure 3a). Remarkably, but consistent with our hypothesis, birinapant converted defective perforin-deficient $\mathrm{T}$ cells into equally potent killers as their wild-type counterparts, particularly when lower ratios of $\mathrm{T}$ cells to target cells were used (Figure 3b, quantitated on right, Supplementary Figure S3). $\mathrm{Pfn}^{-1-}$ NK cells also produced substantially more cytokines that $\mathrm{Pfn}^{+/+}$NK cells (Figure $3 \mathrm{c}$ ), and this also translated into effective target cell killing in the presence of birinapant (Figure 3d, quantitated on right, Supplementary Figure S3). To confirm that $P f n^{-1-}$ CLs were killing via the classical TNF pathway, we exposed $\mathrm{Pfn}^{-1-} \mathrm{CD}^{+} \mathrm{T}$ cells to MC38-Ova targets and performed western blot analysis. Birinapant enhanced cleavage of capase-3 and PARP upon T-cell exposure (Figure $3 e$ ), translating to decreased survival of tumor cell targets in clonogenic assays (Figure 3f). We also detected an increased percentage of tumor cell targets staining positive for cleaved caspase $3 / 7$ upon exposure to $\mathrm{Pfn}^{-1-} \mathrm{CD}^{+} \mathrm{T}$ cells in the presence of birinapant (Figure $3 \mathrm{~g}$, quantitated on right). Interestingly, we also noticed an increase in the frequency of MC38-Ova-CD8 ${ }^{+}$T-cell synapses in which the target cell was caspase $3 / 7$ positive following birinapant treatment (Figure $3 \mathrm{~h}$, quantitated on right). This suggested that $\mathrm{CD}^{+} \mathrm{T}$ cells may be using a membrane-bound form of TNF to kill targets, which is enhanced by birinapant. Taken together, these data demonstrate that perforin is dispensable for the action of birinapant by harnessing the potent pro-apoptotic properties of TNF.

Birinapant promotes bystander and synapse-mediated killing. To further interrogate the mechanism by which birinapant promotes $\mathrm{CL}$ killing at the single cell level, we performed time-lapse microscopy. We labeled perforin-deficient OT-1 T cells (to eliminate rapid granzyme-dependent apoptosis) with Cell Trace Violet (CTV) and monitored their ability to synapse with, and kill MC38-Ova cells. Induction of tumor cell apoptosis was evident by addition of a fluorescent cleaved caspase $3 / 7$ reporter to the assay medium. Figure $4 a$ shows a series of still images captured from Supplementary Movie 1 (supplementary data) in which the $\mathrm{T}$ cells, in the presence of DMSO, fail to kill any of the tumor cell targets over an $8 \mathrm{~h}$ period. However, in the presence of birinapant, target cell apoptosis can be detected by $6 \mathrm{~h}$, and is widespread by $8 \mathrm{~h}$ after exposure to T cells (Figure $4 \mathrm{a}$, and supplementary Movie 2). To interrogate the contribution of soluble TNF in mediating bystander killing, we evaluated the number of tumor cells that underwent apoptosis in the absence of a T-cell synapse. Interestingly, we observed a significant increase in bystander killing in the presence of birinapant (Figure 4b). Furthermore, we found that birinapant increased the frequency of killing that occurred during an immune synapse, prior to CL detachment (Figure 4c).

TNF is expressed on the membrane of CLs where it is processed and shed from the membrane by the matrix metalloprotease, TACE. ${ }^{41}$ Because we observed enhanced CL killing upon immune synapse formation in the presence of birinapant (Figure 4c), we asked if membrane-bound TNF contributed to CL-mediated tumor killing upon treatment. Initially we used the NK cell line, KHYG1, owing to its robust production of readily detectable amounts of TNF. PMA/ Ionomycin induced upregulation of membrane-bound TNF, which was detected by flow cytometry, and as expected, the amount of membrane TNF was further increased by TACE inhibition using marimastat (Figure $4 d$ ). To determine whether NK cells could kill targets via membrane TNF we used $\mathrm{Pfn}^{-1-}$ murine NK cells. A TNF-neutralizing antibody (which blocks soluble and membrane TNF) reduced the cytotoxicity of $\mathrm{Pfn}^{-1-} \mathrm{NK}$ cells to negligible levels (Figure 4e). Although marimastat entirely blocked release of soluble TNF into the supernatant upon tumor cell engagement (Figure 4f) it did not phenocopy the complete block on NK cell killing with anti-TNF (Figure $4 \mathrm{~g}$ ). This suggests that both soluble and membranebound forms of TNF contribute to NK cell cytotoxicity in this context. Furthermore, NK cell killing via membrane TNF (due to marimastat treatment) could be significantly enhanced in the presence of birinapant (Figure 4h, quantitated on right). Thus, birinapant is able to harness both membrane-bound and soluble forms of TNF to kill tumor cells.

PD-L1 suppresses secretion of TNF and cell killing by CL. Checkpoint blockade therapy is thought to reverse T-cell

Figure 2 IAP antagonism promotes TNF-dependent cytotoxic lymphocyte killing. (a) Chromium release assay (4 h) using MC38-Ova cells as targets and OT-I T cells as effectors, in the presence or absence of birinapant $(1 \mu \mathrm{M})$. (b) Chromium release assay (18 h) using MC38-Ova cells as targets and OT-I T cells as effectors, in the presence or absence of birinapant $(1 \mu \mathrm{M})$. (c) Chromium release assay $(4 \mathrm{~h})$ using MC38 cells as targets and murine NK cells as effectors, in the presence or absence of birinapant $(1 \mu \mathrm{M})$. (d) Chromium release assay (18 h) using MC38 cells as targets and murine NK cells as effectors, in the presence or absence of birinapant (1 $\mu \mathrm{M})$. (e) Chromium release assay (18 h) using HeLa cells as targets and KHYG1 NK cells as effectors, in the presence or absence of birinapant $(1 \mu \mathrm{M})$. (f) Chromium release assay (18 h) using MC38-Ova or MC38-Vector cells as targets and OT-I T cells as effectors, in the presence or absence of birinapant (1 $\mu \mathrm{M})$. (g) Chromium release assay (18 h) using MC38-Ova cells as targets and OT-I T cells as effectors, in the presence or absence of birinapant $(1 \mu \mathrm{M})$ and anti-TNF-neutralizing antibody. (h) Chromium release assay (18 h) using MC38 cells as targets and murine NK cells as effectors, in the presence or absence of birinapant $(1 \mu \mathrm{M})$ and anti-TNF-neutralizing antibody. (i) Chromium release assay (18 h) using MC38 cells treated with the indicated concentration of TNF, in the presence or absence of birinapant $(1 \mu \mathrm{M})$ and emricasan $(1 \mu \mathrm{M})$. (j) MC38-Ova cells were treated with TNF $(50 \mathrm{ng} / \mathrm{ml})$ in the presence or absence of birinapant $(1 \mu \mathrm{M})$. At the indicated time-points proteins were analyzed by western blotting. Error bars represent the mean \pm S.E.M. of triplicate determinations from a representative experiment, ${ }^{*} P<0.05$ by unpaired Student's $t$-test 
exhaustion by re-instating cytotoxic function and cytokine secretion. ${ }^{30,31,37}$ Although it has been demonstrated that antiPD-1 therapy can elevate IFN $\gamma$ secretion by $\mathrm{CD}^{+} \mathrm{T}$ cells, ${ }^{36,42}$ fewer studies have focused on the implications of elevated
TNF secretion upon PD-L1/PD-1 disruption. ${ }^{36}$ Because we had shown that birinapant potentiates CL function through TNF, we investigated whether the PD-1/PD-L1 axis modulated TNF secretion by $\mathrm{CD}^{+} \mathrm{T}$ cells. As expected, IFN $\gamma$ a

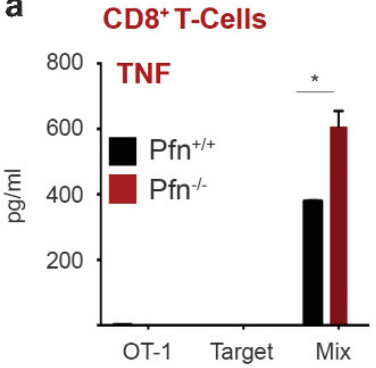

c

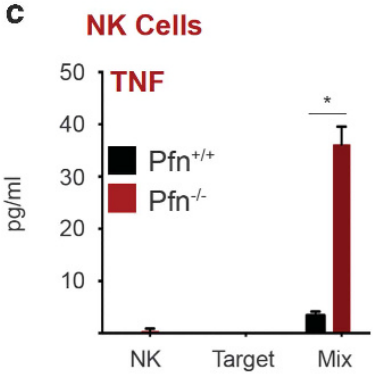

e

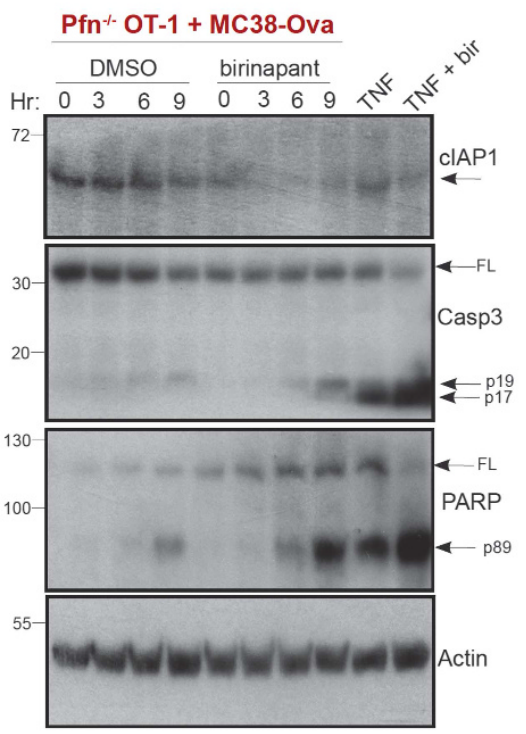

f

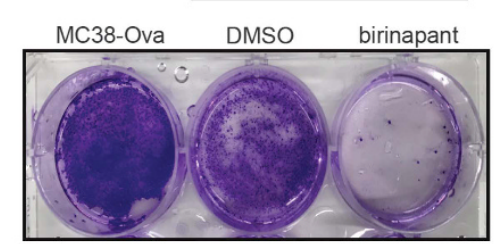

CD8 ${ }^{+}$T-Cells

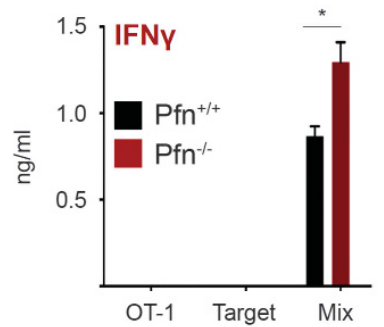

NK Cells

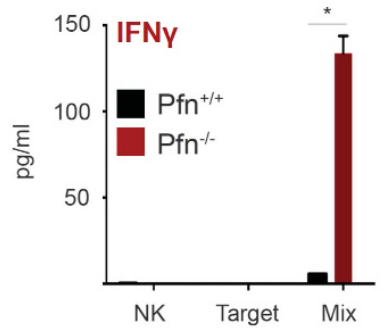

g
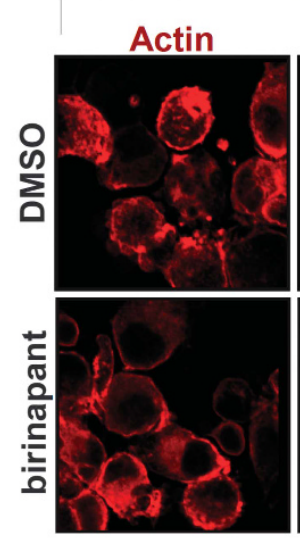

d NK Cells

CD8 ${ }^{+} \mathrm{T}-$ Cells
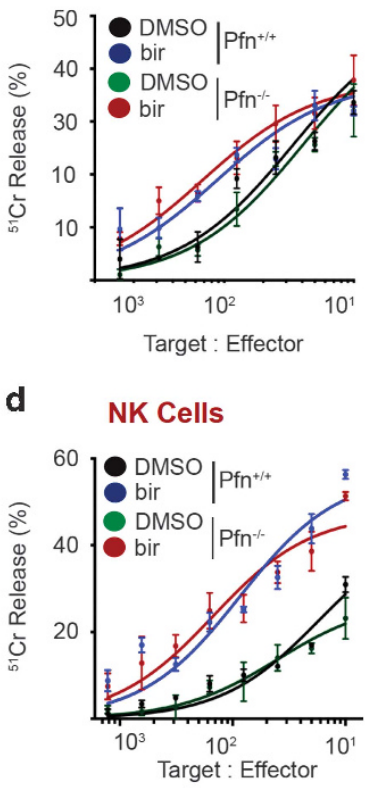
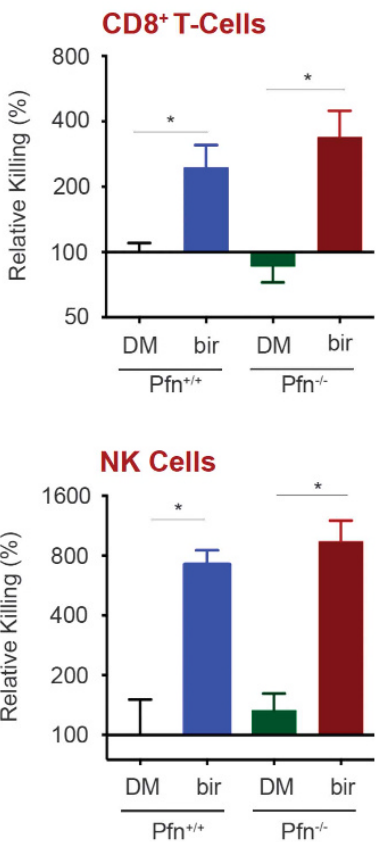

Pfn ${ }^{-1-}$ OT-1 + MC38-Ova
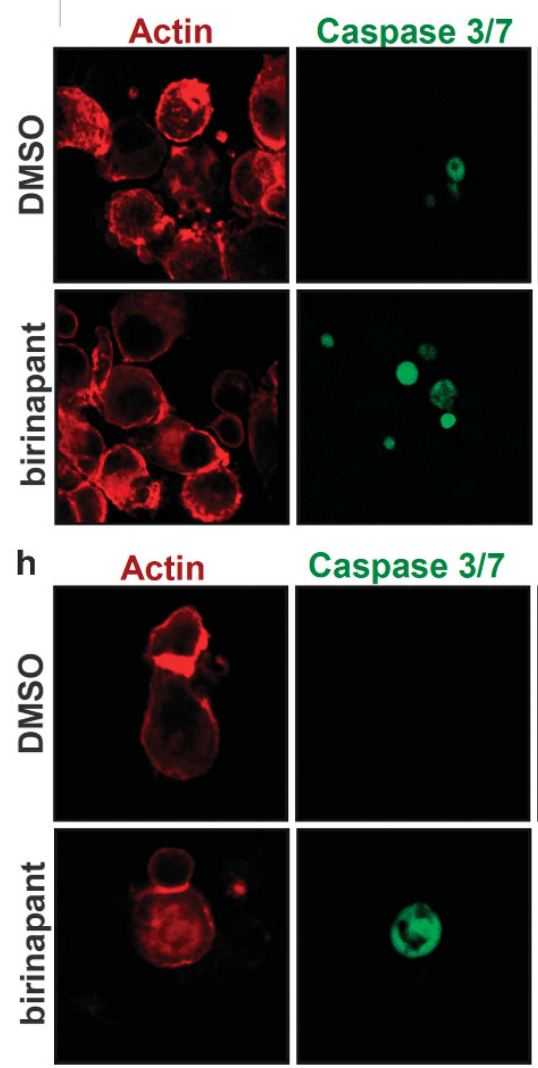

Merge

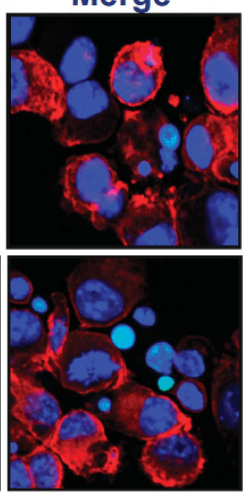

Caspase 3/7 +

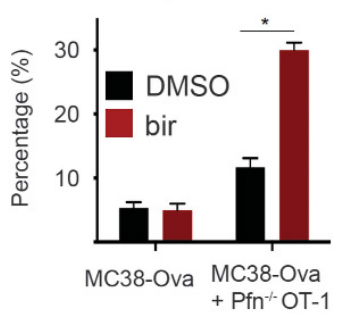

Caspase 3/7

Merge
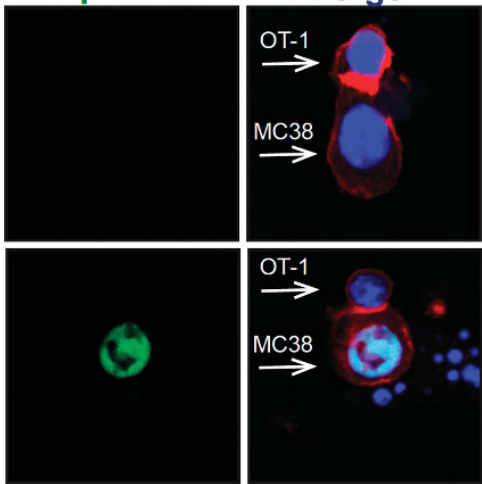
a

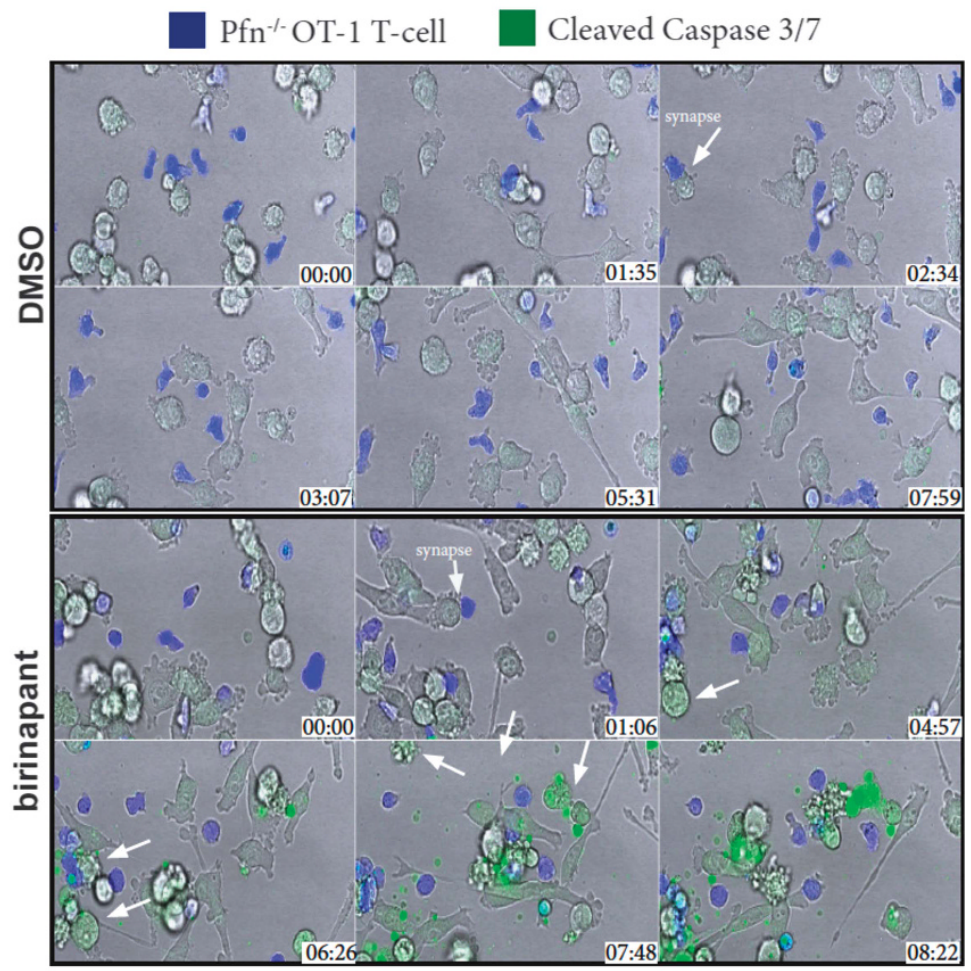

\section{b Bystander Killing}

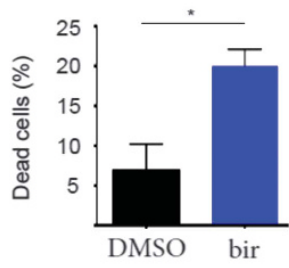

C Synaptic Killing

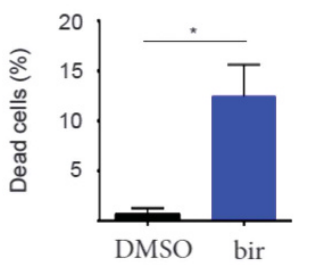

d Membrane Bound TNF

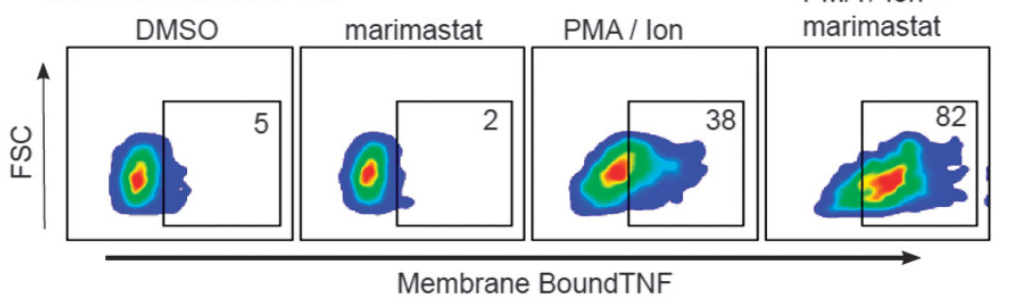

Membrane BoundTNF e $\quad \mathrm{Pfn}^{-1}$ Mouse NK Cells

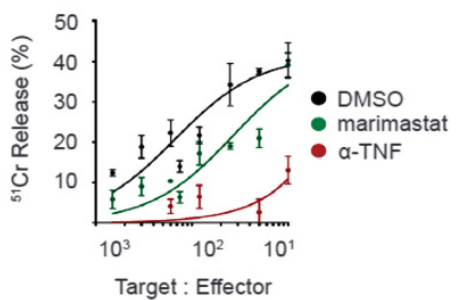

Target : Effector

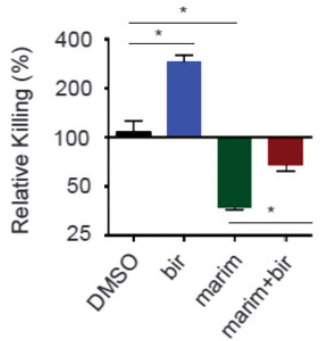

Figure 4 Live imaging reveals that birinapant promotes bystander and TNF-mediated synaptic killing. (a) MC38-Ova cells were seeded in chamber slides, then overlaid with perforin-deficient OT-I T cells. T cells were labeled with cell trace violet (CTV). A cleaved caspase $3 / 7$ reporter and birinapant $(1 \mu \mathrm{M}) / \mathrm{DMSO}$ was added to the co-culture media. Representative still images at the indicated time-points are depicted (hr:min). (b) MC38-Ova cells that became caspase 3/7 positive in the absence of an immune synapse with a T-cell within the $8 \mathrm{~h}$ time span. (c) MC38-Ova cells that became caspase $3 / 7$ positive during an immune synapse with a T-cell within the $8 \mathrm{~h}$ time span. All quantification data are pooled from five separate camera positions across two individual experiments. Error bars represent the mean \pm S.E.M ${ }^{*} P<0.05$ by unpaired Student's $t$-test

Figure 3 IAP antagonism promotes perforin-independent CL killing. (a) MC38-Ova cells were exposed to $P f n^{+/+}$or $P f n^{-1-}$ OT-I T cells. After $5 \mathrm{~h}$, cytokines in supernatants were measured by CBA. (b) Chromium release assay (18 h) using MC38-Ova cells as targets and $\mathrm{Pfn}^{+/+}$or $\mathrm{Pfn}^{-1-}$ OT-I T cells, in the presence or absence of birinapant (1 $\left.\mu \mathrm{M}\right)$. (c) MC38-Ova cells were exposed to $\mathrm{Pfn}^{+/+}$or $\mathrm{Pfn}^{-l-}$ murine NK cells. After $5 \mathrm{~h}$, cytokines in supernatants were measured by CBA. (d) Chromium release assay (18 h) using MC38 cells as targets and Pfn ${ }^{+/+}$or Pfn ${ }^{-1-}$ murine NK cells, in the presence or absence of birinapant $(1 \mu \mathrm{M})$. (e) MC38-Ova cells $\left(2 \times 10^{6}\right)$ were exposed to $2 \times 10^{5}$ Pfn ${ }^{-1-}$ OT-I T cells in the presence or absence of birinapant $(1 \mu \mathrm{M})$. TNF $(50 \mathrm{ng} / \mathrm{ml})$ and birinapant $(1 \mu \mathrm{M})$ were used as positive controls. At the indicated time-points, proteins were analyzed by western blotting. (f) MC38-ova cells $\left(1 \times 10^{6}\right)$ were exposed to $\mathrm{Pfn}^{-1}-$ OT-I T cells $\left(2 \times 10^{5}\right)$. After $48 \mathrm{~h}$, cells were visualized by crystal violet staining. (g-h) MC38-Ova cells were seeded in chamber slides then overlaid with $P f n^{-1-}$ OT-I T cells. After $8 \mathrm{~h}$, cells were fixed, stained as indicated, then visualized by confocal microscopy. A minimum of 50 cells was counted in each condition. Error bars represent the mean \pm S.E.M. of triplicate determinations from a representative experiment, ${ }^{*} P<0.05$ by unpaired Student's $t$ test 
a

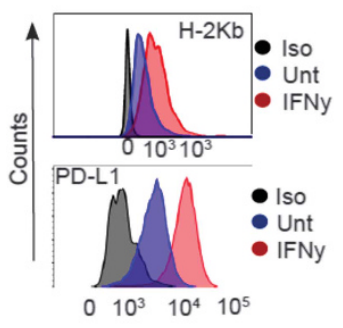

d

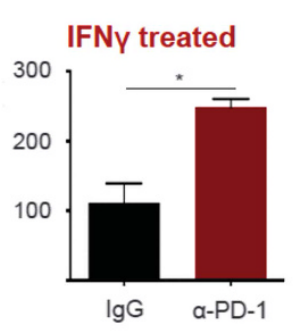

b

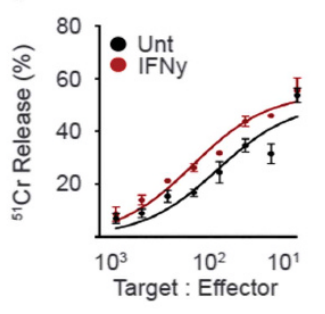

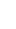

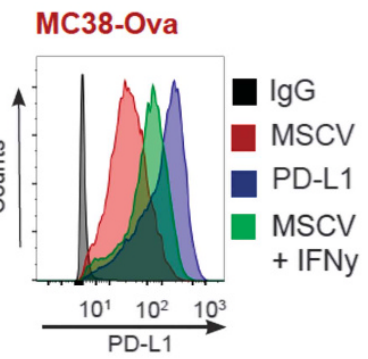

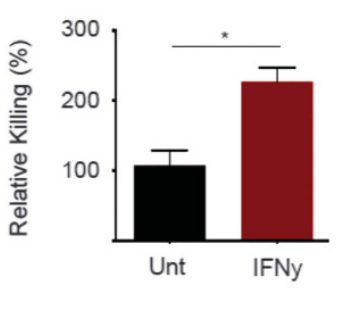

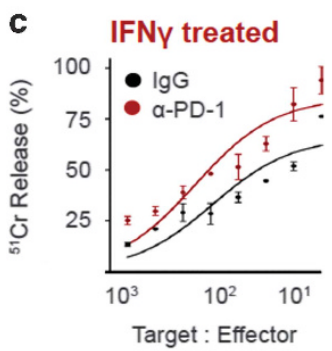

e

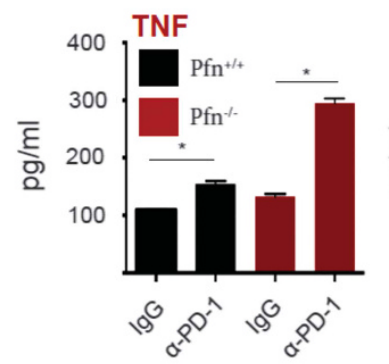

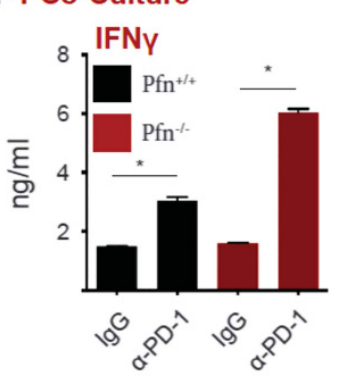

f

MC38 $8^{\text {PDL1 }}$ - OT-1 Co-Culture
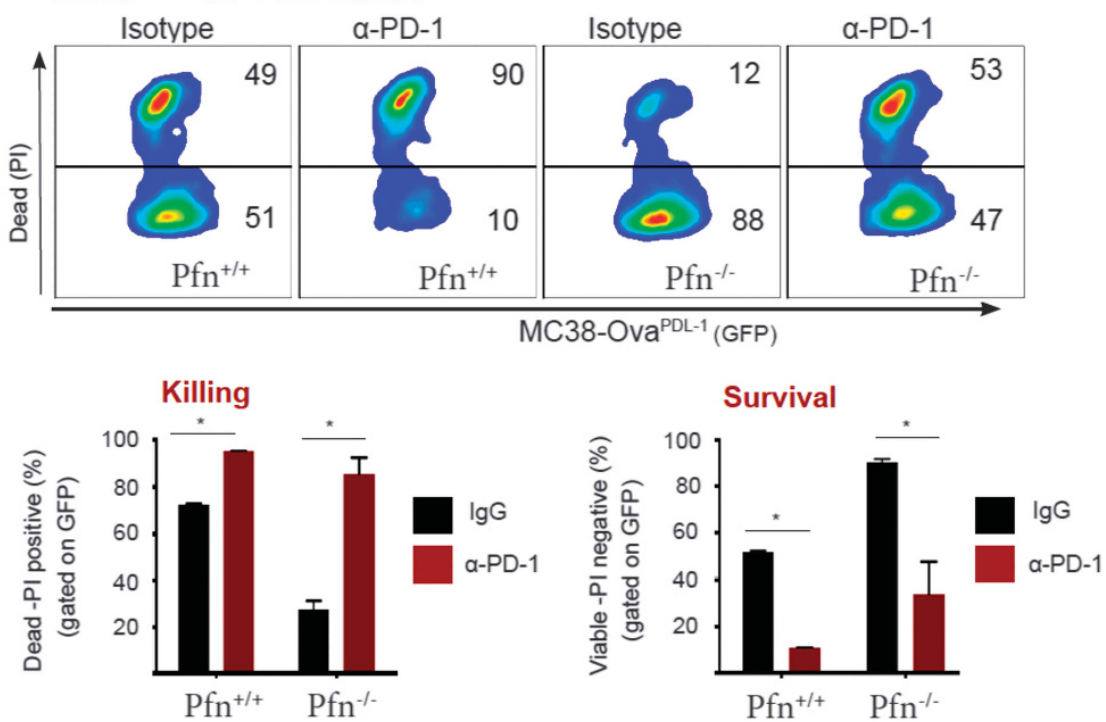

Figure 5 PD-L1 inhibits T-cell secretion of TNF and cytotoxicity. (a) MC38-Ova cells were left untreated or treated with IFN $\gamma$ ( $5 \mathrm{ng} / \mathrm{ml}$ ) for $18 \mathrm{~h}$, then flow cytometry was used to analyze expression of MHC-I (H-2Kb) and PD-L1. (b) MC38-Ova cells were left untreated or treated with IFN $\gamma(5 \mathrm{ng} / \mathrm{ml})$ for $18 \mathrm{~h}$, then used as targets in a chromium release assay with OT-I T cells (18 h). (c) MC38-Ova cells were left untreated or treated with IFN $\gamma(5 \mathrm{ng} / \mathrm{ml})$ for $18 \mathrm{~h}$, then used as targets in a chromium release assay with OT-I T cells (18 h), in the presence of control antibody or anti-PD-1. (d) Flow cytometric analysis of MC38-Ova cells transduced with vector, PD-L1, or treated with IFN $(5 \mathrm{ng} / \mathrm{ml}$ for $18 \mathrm{~h}$ ). (e) MC38 ${ }^{\text {PD-L1 }}$ cells $\left(1 \times 10^{5}\right)$ were exposed to $\mathrm{Pfn}^{+/+}$or Pfn ${ }^{-I-}$ OT-I T cells $\left(1 \times 10^{4}\right)$, in the presence of control antibody or anti-PD- $1(50 \mu \mathrm{g} / \mathrm{ml})$. After $48 \mathrm{~h}$, cytokines in supernatants were measured by CBA. (f) MC38 $8^{\text {DD-L1 }}$ cells $\left(1 \times 10^{5}\right)$ were exposed to Pfn ${ }^{+/+}$or Pfn ${ }^{-1-}$ OT-I T cells $\left(1 \times 10^{4}\right)$, in the presence of control antibody or anti-PD-1 (50 $\left.\mu \mathrm{g} / \mathrm{ml}\right)$. After $48 \mathrm{~h}$, survival was analyzed by PI staining and flow cytometry. Error bars represent the mean \pm S.E.M. of triplicate determinations from a representative experiment, ${ }^{*} P<0.05$ by unpaired Student's $t$-test

upregulated PD-L1 and MHC-I expression on MC38-ova cells (Figure 5a). Indeed, elevated MHC-I expression increased the efficiency of T-cell-mediated killing (Figure $5 b$, quantitated on right). However, under these conditions, neutralization of PD-1 enhanced T-cell killing even further, indicating that PD-L1 was suppressing T-cell effector function (Figure 5c, quantitated). To interrogate the role of PD-L1 in the absence of concurrent MHC-I regulation, we stably expressed PD-L1 on MC38-Ova cells (MC38 ${ }^{\text {PD-L1 }}$ ), (Figure $5 \mathrm{~d}$ ). Initially, we monitored cytokine production in the presence of a control antibody, or a PD-1 neutralizing antibody. Importantly, antagonizing PD-1 leads to significantly higher production of TNF and IFNy, which was amplified in the absence of perforin (Figure 5e,Supplementary Figure S3). Blockade of $\mathrm{PD}-1$ also increased killing of MC38 ${ }^{\mathrm{PD}-\mathrm{L} 1}$ cells by $\mathrm{T}$ cells (Figure 5f, quantitated on right). Importantly, this also 

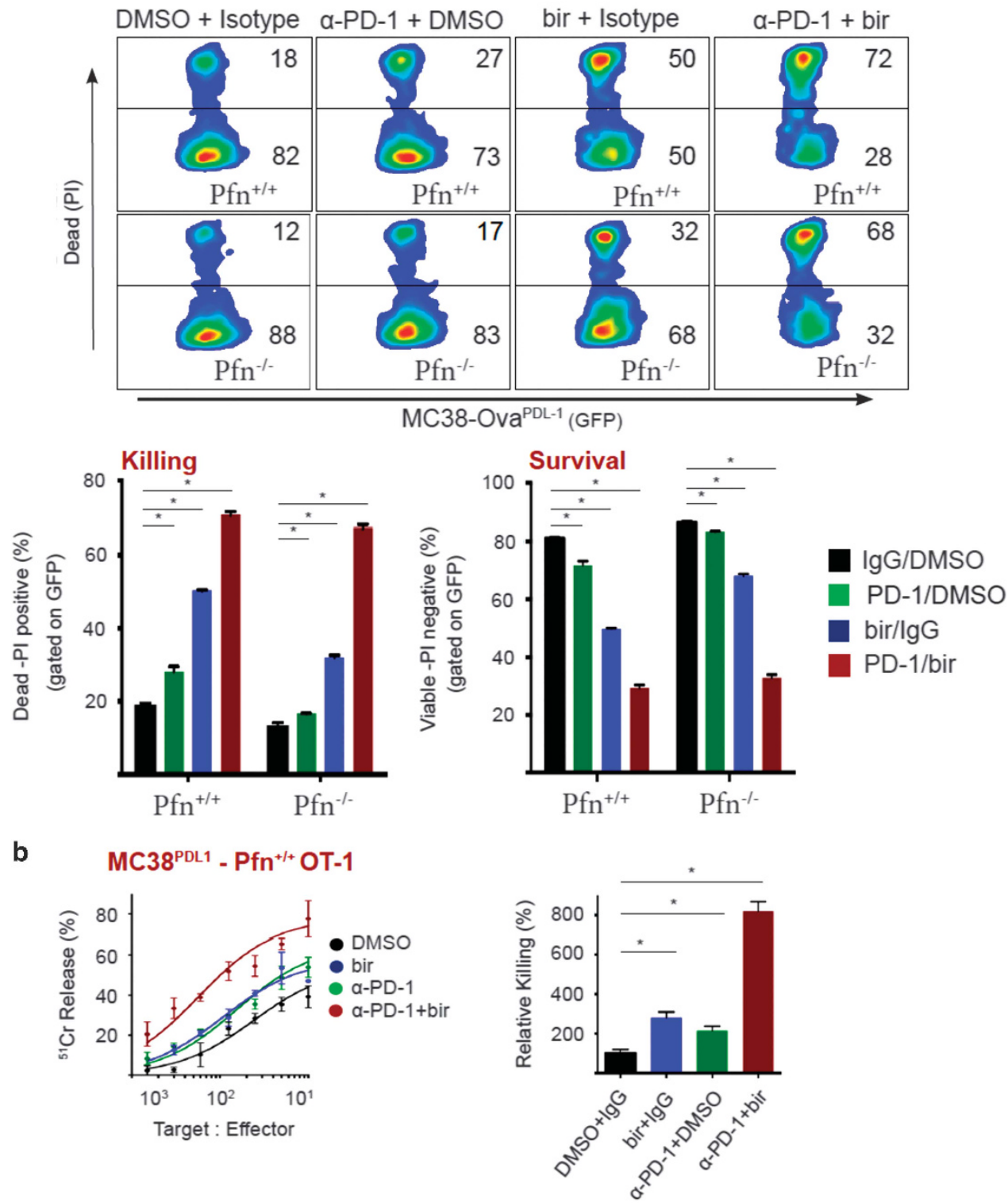

c

\section{MC38 $8^{\text {PDL1 }}$ - Pfn ${ }^{-1-}$ OT-1}
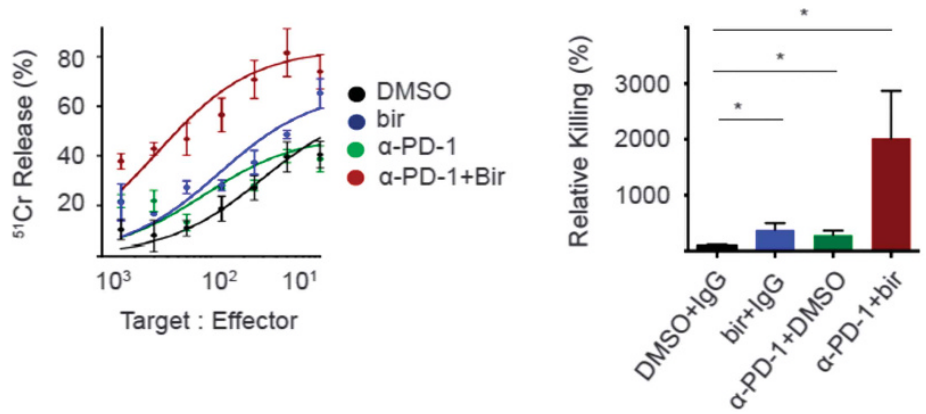

Figure 6 Birinapant increases tumor cell death by cytotoxic lymphocytes, which is further enhanced by PD-1 blockade. (a) MC38 ${ }^{\mathrm{PD}-\mathrm{L} 1}$ cells were exposed to $\mathrm{Pfn}{ }^{+/+}$or $P f n^{-1-}$ OT-I T cells, in the presence or absence of DMSO/birinapant $(1 \mu \mathrm{M})$ and/or control/anti-PD-1 antibody $(10 \mu \mathrm{g} / \mathrm{ml})$. After $48 \mathrm{~h}$, survival was analyzed by PI staining and flow cytometry. (b) Chromium release assay (18 h) using MC38 ${ }^{\mathrm{PD}-\mathrm{L} 1}$ cells as targets and Pfn ${ }^{+/+}$OT-I T cells as effectors, in the presence or absence of DMSO/birinapant (1 $\left.\mu \mathrm{M}\right)$ and/or control/anti-PD-1 antibody $(50 \mu \mathrm{g} / \mathrm{ml})$. (c) Chromium release assay $(18 \mathrm{~h})$ using MC38 ${ }^{\mathrm{PD}-\mathrm{L} 1}$ cells as targets and Pfn ${ }^{-1}$ - OT-I T cells as effectors, in the presence or absence of DMSO/birinapant $(1 \mu \mathrm{M})$ and/or control/anti-PD-1 antibody $(50 \mu \mathrm{g} / \mathrm{ml})$. Error bars represent the mean \pm S.E.M. of triplicate determinations from a representative experiment, ${ }^{*} P<0.05$ by unpaired Student's $t$-test 
occurred in the absence of perforin, demonstrating the importance of enhanced cytokine production in checkpoint blockade anti-tumor action. Taken together, PD-1 ligation by tumor cell expressed PD-L1 suppresses T-cell effector function (cytokine production and target cell death).

Inhibition of IAPs by birinapant increases perforinindependent tumor cell killing by CLs, which is further enhanced by co-inhibition of PD-L1. Because we had demonstrated that birinapant sensitized tumor cells to CL-derived TNF (Figure 2), and tumor cells suppress TNF production through PD-1 ligation (Figure 5), we asked if co-inhibition of immune checkpoint could enhance the efficacy of birinapant. Anti-PD-1 or birinapant treatment alone decreased the survival of $\mathrm{MC} 38^{\mathrm{PD}-\mathrm{L} 1}$ cells upon T-cell exposure. However, the combination of these two agents reduced the viability of target cells to just 28 percent (Figure 6a, quantitated on right). Importantly, we also observed a dramatic decrease in tumor cell survival using $\mathrm{Pfn}^{-1-} \mathrm{T}$ cells. Thus, effective tumor cell killing upon inhibition of IAPs and PD-L1 occurs in a perforin-independent, TNF-dependent fashion. We also used a chromium release assay to examine the killing kinetics upon co-inhibition. Although anti-PD-1 or birinapant alone enhanced T-cell killing kinetics, combining these two agents resulted in markedly enhanced killing (Figure 6b). Again, we observed the same level of killing in the complete absence of perforin (Figure 6c).

\section{Discussion}

Although it is widely accepted that IAP antagonists promote tumor cell death by sensitizing them to TNF-induced apoptosis, the majority of studies that demonstrate this phenomenon have been conducted in vitro. Cell lines that produce TNF in response to SMs are usually sensitive to these agents as a mono-therapy due to autocrine/paracrine TNF signaling. ${ }^{6,7,8}$ However, those cells that fail to produce TNF upon IAP loss can often be killed by exogenous addition of TNF in order to invoke apoptosis. ${ }^{6,7,8}$ The mechanisms by which Smacmimetics display anti-tumor efficacy in vivo are therefore likely to be complex. First, there are multiple immune cell subtypes, particularly CLs and monocytes/macrophages, that produce TNF and could supply the TNF required for SM anti-tumor efficacy in vivo. This is evident from studies demonstrating that SM synergize with inflammatory adjuvants, which trigger a systemic increase in TNF levels, which is released by responder cells of the innate immune system. ${ }^{15,18}$ Second, there is emerging evidence that IAP antagonists promote antitumor immunity independently from direct induction of tumor cell apoptosis. ${ }^{14}$ For example, the IAP antagonist, compound $A$, has been shown to inhibit tumor growth through inflammatory destruction of tumor vasculature. ${ }^{43}$ This occurred using tumor cells (murine melanoma B16 cells) that are completely refractory to TNF/SM-induced cell death. Furthermore, antagonizing IAPs appears to promote anti-tumor immunity through enhancing effector T-cell co-stimulation and proliferation. This occurs through triggering alternative, NIK-dependent NF- $k \mathrm{~B}$ activation in response to antigen or CD3/CD28 stimulation. ${ }^{44}$ Together, these studies highlight that the immune system may

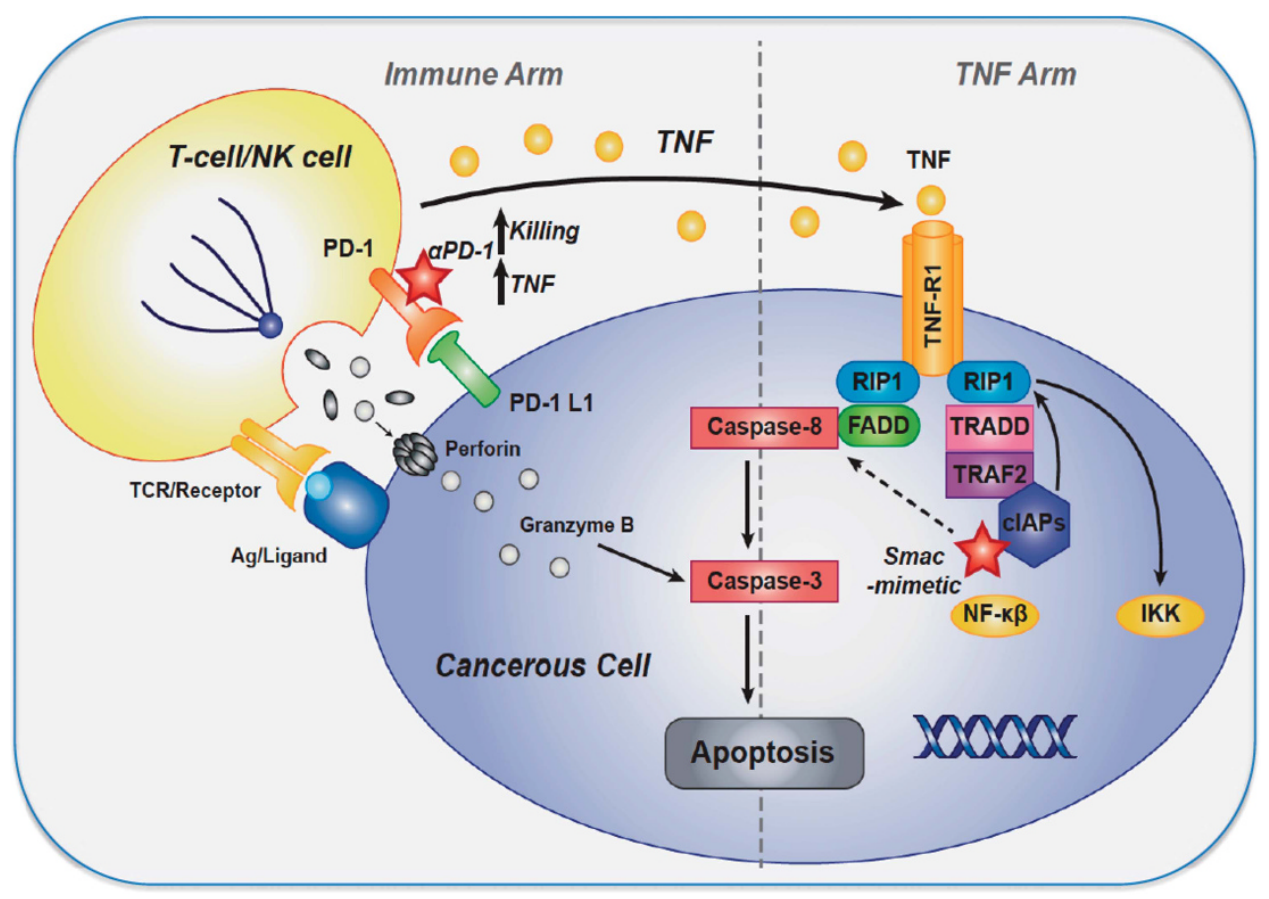

Figure 7 Schematic representation of pathways leading to cytotoxic lymphocyte killing upon IAP or PD-1 antagonism. Ligation of TCR with cognate tumor antigen or NK cell activating receptor stimulation drives TNF production. PD-L1 expression on tumor cells, dampens signaling cascades that drive TNF production and perforin/granzyme-mediated apoptosis. Furthermore, tumor cell expression of clAP1/2 protects them from apoptosis mediated by TNF released from CLs. Thus co-inhibition of PD-L1 and IAPs increases TNF production from CLs, and decreases the TNF threshold for apoptosis induction 
be utilized to improve the efficacy of SMs; however, a better understanding of how SMs modulate tumor immunity is required to take full advantage of this opportunity.

Many diverse solid tumor types are heavily infiltrated with CLs, and this often predicts patient prognosis. ${ }^{22}$ Therefore, harnessing these cells as vehicles to deliver TNF to the tumor site may be very effective therapeutically. Indeed, $C D 8^{+} \mathrm{T}$ cells trigger TNF synthesis upon tumor antigen recognition, avoiding robust TNF production in non-malignant tissue. Similarly, NK cells produce robust quantities of TNF upon ligation of activating receptors through tumor-expressed ligands. However, how SMs modulate the killing capacity of these cells remains unexplored. Here we demonstrated that CL-mediated killing of tumor cells is dramatically improved in the presence of SM. This occurs through TNF production upon antigen recognition or NK-activating receptor ligation. Importantly, we found that tumor cells suppress this route to their demise by dampening T-cell TNF production through expression of PD-L1. Furthermore, our data demonstrating that PD-1 blockade/IAP antagonism improves CL killing in the complete absence of perforin, highlights the importance of cytokines in the efficacy of immune checkpoint therapy (Figure 7).

Much attention has been given to the anti-tumor efficacy of checkpoint blockade therapy, which is mediated by $\mathrm{T}$ cells. However, sporadic reports suggest that the function of NK cells is also enhanced via a similar mechanism. ${ }^{45}$ Thus, such agents, particularly when combined with SMs, may promote NK cell-dependent anti-tumor immunity. Certainly, biologics that specifically enhance NK cell cytokine production could be potently enhance the efficacy of SM. This type of treatment is likely to be effective against hematological tumors, which are characterized by suppressed NK cell effector function prior to chemotherapy or allogeneic stem cell plantation. ${ }^{46,47} \mathrm{NK}$ cells can also lyse tumor cells through the TRAIL/Fas pathway, independently of perforin. Because it is known that SMs can greatly sensitize tumor cells to death mediated by TRAIL or Fas ligand, ${ }^{48}$ antagonizing IAPs may improve this pathway in tumors that express DR4/5 or CD95. More studies will be required to understand the role of these death ligands in the efficacy of SMs in vivo.

Taken together, we have demonstrated that IAPs and PD-L1 protect tumor cells from the pro-apoptotic function of TNF derived from CLs. Thus, co-inhibition of these molecules markedly sensitizes tumor cells to killing by CLs (Figure 7). We believe the present data warrant further evaluation of these drugs in treating diverse cancer types. Importantly, clinical trials in which SMs will be administered in combination with immune checkpoint blockade are soon to commence (ClinicalTrials.gov: NCT02587962, NCT02890069). Thus, our data provide important information regarding the mode of action upon combining these agents in patients, and provide an opportunity to improve their efficacy through mechanistic understanding.

\section{Materials and Methods}

The cell lines MC38 and HeLa were cultured in RPMI medium (GIBCO, Melbourne, Victoria, Australia; Invitrogen, Scoresby, Victoria, Australia) supplemented with $10 \%$ FCS (Thermo Scientific, Scoresby, Victoria, Australaia), penicillin/streptomycin (Gibco), and incubated at $37{ }^{\circ} \mathrm{C}$ in $5 \% \mathrm{CO}_{2}$. Primary NK cells were isolated from C57BI/6 splenocytes, using a negative selection isolation kit (Stem Cell Technologies, Tullamarine, Victoria, Australia). Murine NK cells were cultured in RPMI medium supplemented with $10 \%$ fetal calf serum, L-glutamine, penicillin/streptomycin, nonessential amino acids, sodium pyruvate, HEPES, $\beta$-2-mercaptoethanol (Calbiochem, Macquarie Park, New South Wales, Australia), and $1000 \mathrm{IU} / \mathrm{ml}$ recombinant human IL-2 (ROCHE, Sydney, New South Wales, Australia), at $37^{\circ} \mathrm{C}$ in a $5 \% \mathrm{CO}_{2}$. Primary CLs were isolated from the spleens of C57BI/6.OT-I or OT-I.Prf ${ }^{-1}$ mice and activated with $\mathrm{OVA}_{257}$ peptide. Activated CLs were generally used on day 5-10. CLs were cultured as murine NK cells, with $100 \mathrm{IU} / \mathrm{ml}$.

Cytotoxic assays. $\mathrm{CL}$ activity was measured using a standard chromium release assay as follows: of $1 \times 10^{6}$ targets were labeled with $100 \mu \mathrm{Ci}$ of $51 \mathrm{Cr}$ (Perkin Elmer, Melbourne, Victoria, Australia) and added to V bottom plates. CLs cells were then added to the targets at the indicated effector to target $(E: T)$ ratios. After 4 or $18 \mathrm{~h}$ at $37^{\circ} \mathrm{C}$ in $5 \% \mathrm{CO}_{2}$, supernatants were harvested, and the level of ${ }^{51} \mathrm{Cr}$ was quantified by a gamma counter (Wallac Wizard). Percentage specific killing was determined using the formula: (Sample ${ }^{51} \mathrm{Cr}$ release - Spontaneous ${ }^{51} \mathrm{Cr}$ release)/ (Total ${ }^{51} \mathrm{Cr}$ release - Spontaneous ${ }^{51} \mathrm{Cr}$ release) $\times 100$, and represented as a Michaelis-Menten kinetic trend. All assays were performed using triplicate wells. The rate of killing in the control is represented as $100 \%$ killing and treatment groups compared with this value.

Antibodies. Neutralizing antibodies: anti-TNF (Biolegend, San Diego, CA, USA, clone MP6-XT22), anti-PD-1 (BioXCell, Lebanon, NH, USA, clone Rpmi-14). Antibodies for western blot: anti caspase 3, anti-PARP, anti clAP1 (Cell Signaling, Danvers, MA, USA), anti tubulin (Rockland, Limerick, PA, USA). Antibodies for immunofluorescence: anti-TNF (Biolegend, clone MP6-XT22), IFN $\gamma$ (eBiosciences, Scoresby, Victoria, Australia, clone XMG1.2), Tubulin (Rockland). RhodaminePhalloidin was used to detect actin. Secondary antibodies conjugated to Alexa fluorophores and ProLong antifade with DAPI were purchased from Molecular Probes (Scoresby, Victoria, Australia).

Cytokine bead array (CBA). Cytokines were detected using a mouse inflammation CBA kit (BD Biosciences, 552364) as per manufacturer's instructions. Beads were analyzed on a FACS Verse (BD Biosciences, North Ryde, New South Wales, Australia). All assays were analyzed using triplicate determinations.

Immunofluorescent fixed microscopy. Cells were adhered onto eight-well chamber slides overnight, prior to addition of effector cells for the indicated time periods. Cells were then fixed, permeabilized, and labeled with primary Abs, followed by detection with Alexa Fluor-conjugated secondary Abs and mounted in Prolong antifade containing DAPI (Molecular Probes). The slides were imaged using a FV1000 confocal microscope (Olympus, NY, USA). CLs selected for quantitation had a single contact site with one tumor cell, indicating a single synapse event. The percentage of $T$ cells that were positive for the indicated marker (cytokines or caspase positivity), in a synapse or not, was quantitated manually by confocal microscopy. A minimum of 100 cells was counted in each condition.

Time-lapse microscopy. MC38-Ova cells were seeded into each well of an eight-well chamber slide (lbidi, Munich, Germany) and incubated overnight at $37^{\circ} \mathrm{C} / 10 \%$ CO2. OT-I T cells were labeled with CTV (Molecular Probes), then added to adherent targets, in media containing caspase $3 / 7$ detection reagent (ThermoFischer). Chamber slides were mounted on a heated stage within a temperature-controlled chamber maintained at $37^{\circ} \mathrm{C}$, and constant $\mathrm{CO} 2$ concentrations (5 or $7 \%$ ) were infused using a gas incubation system with active gas mixer ('The Brick'; Ibidi). Optical sections were acquired through sequential scans or Brightfield/DIC on a TCS SP5 confocal microscope (Leica Microsystems, Deerfield, IL, USA) using a $\times 40$ (NA 0.85) air objective and Leica LAS AF software. Image analysis was performed using Meta-Morph Imaging Series 7 software (Universal Imaging, Downingtown, PA, USA).

\section{Conflict of Interest}

John Silke was previously a member of the TetraLogic scientific advisory board. The remaining authors declare no conflict of interest.

Acknowledgements. The work was supported by the National Health and Medical Research Council of Australia (NHMRC), grants 1081376 and 1079319; fellowships 1058190 to CJK and 1107149 to JS and the WWCR grant 15-0042 to NL. This work was made possible through Victorian State Government Operational Infrastructure Support and Australian Government NHMRC IRIISS (9000220). 
1. Gyrd-Hansen M, Meier P. IAPs: from caspase inhibitors to modulators of NF-kappaB, inflammation and cancer. Nat Rev Cancer 2010; 10: 561-574.

2. Silke J, Vucic D. IAP family of cell death and signaling regulators. Methods Enzymol 2014; 545: 35-65.

3. O'Riordan MX, Bauler LD, Scott FL, Duckett CS. Inhibitor of apoptosis proteins in eukaryotic evolution and development: a model of thematic conservation. Dev Cell 2008; 15: 497-508.

4. Galban S, Duckett CS. XIAP as a ubiquitin ligase in cellular signaling. Cell Death Differ 2010; 17: 54-60.

5. Mahoney DJ, Cheung HH, Mrad RL, Plenchette S, Simard C, Enwere E et al. Both cIAP1 and CIAP2 regulate TNFalpha-mediated NF-kappaB activation. Proc Natl Acad Sci USA 2008; 105: 11778-11783.

6. Vince JE, Wong WW, Khan N, Feltham R, Chau D, Ahmed AU et al. IAP antagonists target CIAP1 to induce TNFalpha-dependent apoptosis. Cell 2007; 131: 682-693.

7. Varfolomeev E, Blankenship JW, Wayson SM, Fedorova AV, Kayagaki N, Garg P et al. IAP antagonists induce autoubiquitination of c-IAPs, NF-kappaB activation, and TNFalphadependent apoptosis. Cell 2007; 131: 669-681.

8. Petersen SL, Wang L, Yalcin-Chin A, Li L, Peyton M, Minna J et al. Autocrine TNFalpha signaling renders human cancer cells susceptible to Smac-mimetic-induced apoptosis. Cancer Cell 2007; 12: 445-456.

9. Brumatti G, Ma C, Lalaoui N, Nguyen NY, Navarro M, Tanzer MC et al. The caspase-8 inhibitor emricasan combines with the SMAC mimetic birinapant to induce necroptosis and treat acute myeloid leukemia. Sci Transl Med 2016; 8: 339ra369.

10. McComb S, Aguade-Gorgorio J, Harder L, Marovca B, Cario G, Eckert C et al. Activation of concurrent apoptosis and necroptosis by SMAC mimetics for the treatment of refractory and relapsed ALL. Sci Transl Med 2016; 8: 339ra370.

11. Bertrand MJ, Milutinovic S, Dickson KM, Ho WC, Boudreault A, Durkin J et al. clAP1 and cIAP2 facilitate cancer cell survival by functioning as E3 ligases that promote RIP1 ubiquitination. Mol Cell 2008; 30: 689-700.

12. Lalaoui N, Hanggi K, Brumatti G, Chau D, Nguyen NN, Vasilikos L et al. Targeting p38 or MK2 enhances the anti-leukemic activity of Smac-mimetics. Cancer Cell 2016; 30: 499-500.

13. Tanzer MC, Khan N, Rickard JA, Etemadi N, Lalaoui N, Spall SK et al. Combination of IAP antagonist and IFNgamma activates novel caspase-10- and RIPK1-dependent cell death pathways. Cell Death Differ 2017; 24: 481-491.

14. Chesi M, Mirza NN, Garbitt VM, Sharik ME, Dueck AC, Asmann YW et al. IAP antagonists induce anti-tumor immunity in multiple myeloma. Nat Med 2016; 22: 1411-1420.

15. Beug ST, Tang VA, LaCasse EC, Cheung HH, Beauregard CE, Brun J et al. Smac mimetics and innate immune stimuli synergize to promote tumor death. Nat Biotechnol 2014; 32: 182-190.

16. Guicciardi ME, Krishnan A, Bronk SF, Hirsova P, Griffith TS, Gores GJ. Biliary tract instillation of a SMAC mimetic induces TRAIL-dependent acute sclerosing cholangitis-like injury in mice. Cell Death Dis 2017; 8: e2535.

17. Marschall V, Fulda S. Smac mimetic-induced upregulation of interferon-beta sensitizes glioblastoma to temozolomide-induced cell death. Cell Death Dis 2015; 6: e1888.

18. Dobson CC, Naing T, Beug ST, Faye MD, Chabot J, St-Jean M et al. Oncolytic virus synergizes with Smac mimetic compounds to induce rhabdomyosarcoma cell death in a syngeneic murine model. Oncotarget 2017; 8: 3495-3508.

19. Martinez-Lostao L, Anel A, Pardo J. How do cytotoxic lymphocytes kill cancer cells? Clin Cancer Res 2015; 21: 5047-5056.

20. Bracci L, Schiavoni G, Sistigu A, Belardelli F. Immune-based mechanisms of cytotoxic chemotherapy: implications for the design of novel and rationale-based combined treatments against cancer. Cell Death Differ 2014; 21: 15-25.

21. Galon J, Costes A, Sanchez-Cabo F, Kirilovsky A, Mlecnik B, Lagorce-Pages C et al. Type, density, and location of immune cells within human colorectal tumors predict clinical outcome. Science 2006; 313: 1960-1964.

22. Loi S, Michiels S, Salgado R, Sirtaine N, Jose V, Fumagalli D et al. Tumor infiltrating lymphocytes are prognostic in triple negative breast cancer and predictive for trastuzumab benefit in early breast cancer: results from the FinHER trial. Ann Oncol 2014; 25: 1544-1550.

23. Gooden MJ, de Bock GH, Leffers N, Daemen T, Nijman HW. The prognostic influence of tumour-infiltrating lymphocytes in cancer: a systematic review with meta-analysis. $\mathrm{Br} J$ Cancer 2011; 105: 93-103.

24. Morvan MG, Lanier LL. NK cells and cancer: you can teach innate cells new tricks. Nat Rev Cancer 2016; 16: 7-19
25. Guillerey C, Huntington ND, Smyth MJ. Targeting natural killer cells in cancer immunotherapy. Nat Immunol 2016; 17: 1025-1036.

26. Fauriat $C$, Just-Landi S, Mallet F, Arnoulet $C$, Sainty D, Olive D et al. Deficient expression of NCR in NK cells from acute myeloid leukemia: Evolution during leukemia treatment and impact of leukemia cells in NCRdull phenotype induction. Blood 2007; 109: 323-330.

27. Cullen SP, Brunet M, Martin SJ. Granzymes in cancer and immunity. Cell Death Differ 2010; 17: $616-623$

28. Matsushita H, Hosoi A, Ueha S, Abe J, Fujieda N, Tomura M et al. Cytotoxic T lymphocytes block tumor growth both by lytic activity and IFNgamma-dependent cell-cycle arrest. Cancer Immunol Res 2015; 3: 26-36.

29. Calzascia T, Pellegrini M, Hall H, Sabbagh L, Ono N, Elford AR et al. TNF-alpha is critical for antitumor but not antiviral T cell immunity in mice. J Clin Invest 2007; 117: 3833-3845.

30. Jiang Y, Li Y, Zhu B. T-cell exhaustion in the tumor microenvironment. Cell Death Dis 2015; 6: e1792.

31. Freeman GJ, Wherry EJ, Ahmed R, Sharpe AH. Reinvigorating exhausted HIV-specific T cells via PD-1-PD-1 ligand blockade. J Exp Med 2006; 203: 2223-2227.

32. Pardoll DM. The blockade of immune checkpoints in cancer immunotherapy. Nat Rev Cancer 2012; 12: 252-264.

33. Chemnitz JM, Parry RV, Nichols KE, June CH, Riley JL. SHP-1 and SHP-2 associate with immunoreceptor tyrosine-based switch motif of programmed death 1 upon primary human $T$ cell stimulation, but only receptor ligation prevents T cell activation. J Immunol 2004; 173 : 945-954.

34. Nishimura H, Nose M, Hiai H, Minato N, Honjo T. Development of lupus-like autoimmune diseases by disruption of the PD-1 gene encoding an ITIM motif-carrying immunoreceptor. Immunity 1999; 11: 141-151.

35. Keir ME, Butte MJ, Freeman GJ, Sharpe AH. PD-1 and its ligands in tolerance and immunity. Annu Rev Immunol 2008; 26: 677-704.

36. Wei F, Zhong S, Ma Z, Kong H, Medvec A, Ahmed R et al. Strength of PD-1 signaling differentially affects T-cell effector functions. Proc Natl Acad Sci USA 2013; 110: E2480-E2489.

37. Kearney CJ, Brennan AJ, Darcy PK, Oliaro J. The role of the immunological synapse formed by cytotoxic lymphocytes in immunodeficiency and anti-tumor immunity. Crit Rev Immunol 2015; 35: 325-347.

38. Dustin ML. The immunological synapse. Cancer Immunol Res 2014; 2: 1023-1033.

39. Young JD, Liu CC, Persechini PM, Cohn ZA. Perforin-dependent and -independent pathways of cytotoxicity mediated by lymphocytes. Immunol Rev 1988; 103: 161-202.

40. Jenkins MR, Rudd-Schmidt JA, Lopez JA, Ramsbottom KM, Mannering SI, Andrews DM et al. Failed CL/NK cell killing and cytokine hypersecretion are direCLy linked through prolonged synapse time. J Exp Med 2015; 212: 307-317.

41. Black RA, Rauch CT, Kozlosky CJ, Peschon JJ, Slack JL, Wolfson MF et al. A metalloproteinase disintegrin that releases tumour-necrosis factor-alpha from cells. Nature 1997; 385: 729-733.

42. Pilon-Thomas S, Mackay A, Vohra N, Mule JJ. Blockade of programmed death ligand 1 enhances the therapeutic efficacy of combination immunotherapy against melanoma. J Immunol 2010; 184: 3442-3449.

43. Witt A, Seeger JM, Coutelle O, Zigrino P, Broxtermann P, Andree M et al. IAP antagonization promotes inflammatory destruction of vascular endothelium. EMBO Rep 2015; 16 : 719-727.

44. Dougan M, Dougan S, Slisz J, Firestone B, Vanneman M, Draganov D et al. IAP inhibitors enhance co-stimulation to promote tumor immunity. J Exp Med 2010; 207: 2195-2206.

45. Benson DM Jr., Bakan CE, Mishra A, Hofmeister CC, Efebera Y, Becknell B et al. The PD-1/PD-L1 axis modulates the natural killer cell versus multiple myeloma effect: a therapeutic target for CT-011, a novel monoclonal anti-PD-1 antibody. Blood 2010; 116: 2286-2294.

46. Kearney CJ, Ramsbottom KM, Voskoboinik I, Darcy PK, Oliaro J. Loss of DNAM-1 ligand expression by acute myeloid leukemia cells renders them resistant to NK cell killing. Oncoimmunology 2016; 5: e1196308.

47. Handgretinger R, Lang P, Andre MC. Exploitation of natural killer cells for the treatment of acute leukemia. Blood 2016; 127: 3341-3349.

48. Fulda S. Promises and challenges of Smac mimetics as cancer therapeutics. Clin Cancer Res 2015; 21: 5030-5036.

\section{Supplementary Information accompanies this paper on Cell Death and Differentiation website (http://www.nature.com/cdd)}

